groups accounted for $91 \%, 4 \%, 2 \%$ and $3 \%$ respectively at FP clinic. At STD clinic, almost all subjects were Chinese. The prevalence rate of trichomoniasis was $0.36 \%$ at FP clinic and $0.0 \%$ at STD clinic. Our findings suggested no association between contraceptive methods used and trichomoniasis infection at FP clinic. At STD clinic, it was observed that high risk for STIs acquisition was not associated with trichomoniasis positivity. The data demonstrated that the prevalence of trichomoniasis was very low at FP clinic and even absent at STD clinic. On the other hand, the high prevalence rates of other STIs among sex workers found from this survey suggested the need for more active interventions focused on this group.

\section{P3.095 EXPERIENCES FROM WORKING WITH SEXUALLY TRANSMITTED INFECTIONS AND RELATED ISSUES AMONG TEENAGERS AND YOUTH IN TVER, RUSSIA}

doi:10.1136/sextrans-2013-051184.0554

\begin{abstract}
'M Rozova, ${ }^{1} \mathrm{O}$ Beilina, ${ }^{1} \mathrm{~K}$ Koniuchova, ${ }^{2} \mathrm{~A}$ Savicheva, ${ }^{3} \mathrm{E}$ Sokolovskiy, ${ }^{4} \mathrm{M}$ Domeika, ${ }^{5} \mathrm{M}$ Unemo, Eastern European Network for SexualReproductive Health. 'Avaev's Center of Specialized Medical Aid, Tver, Russian Federation; ${ }^{2}$ Ott Institute of Obstetrics and Gynecology Academy of Medical Sciences of Russian Federation, St Petersburg, Russian Federation; ${ }^{3}$ Pavlov State Medical University of St Petersburg, St Petersburg, Russian Federation, St Petersburg, Russian Federation; ${ }^{4}$ Department of Control and Prevention of Communicable Diseases, Uppsala County Council, Uppsala, Sweden; ${ }^{5}$ WHO Collaborating Centre for Gonorrhoea and other STIs, Örebro, Sweden, Örebro, Sweden
\end{abstract}

Background The prevalence of sexually transmitted infections in Russia is high. Young sexually active individuals it is at highest risk to be infected, therefore increased access for consultations and testing is of great importance.

Methods. The data was collected during the site visit from the records of the Center in February, 2013.

Results The Regional Center for Prevention of the Reproductive Health of Teenagers and Youth "Your world.ru" (Твой мир.ru) was established in Tver, Russia in 2006. One of the multiple activities of the centre is prophylaxis and early detection of reproductive tract disorders, including STI and HIV infections. Medical and psychological help for the young population, aged from 15 to 24 years, of Tver city and region of Tver is provided free of charge by a team including young medical professionals, namely dermatovenereologists, gynaecologists, endocrinologists, urologists-andrologists and psychologists. In 2012, 2,000 young persons (more than 6,000 visits) attended the STI centre for testing and a genital tract infection was diagnosed in $15.3 \%$ of these. Chlamydia trachomatis was detected in $8.8 \%$ (71/805) and Neisseria gonorrhoeae in $4.0 \%(8 / 202)$ of the young persons tested. During the same year three new cases of syphilis and nine cases of HIV were also diagnosed. It is of grave concern that spread of HIV among the young population of Tver is exclusively sexual and is increasing! Conclusion The STI morbidity of the young population, aged 15-24 years, is high in Tver and Tver region, Russia. Among the risk factors for acquiring STIs in Tver and Tver region are early sexual debut, active sexual life with frequent change of sexual partners, casual sex and unprotected sex. More active sexual education within this young age group is essential.

\section{P3.096 HIV AND HCV PREVALENCE AND RISKY BEHAVIORS AMONG NEEDLE EXCHANGE PROGRAM USERS IN ALBANIA}

doi:10.1136/sextrans-2013-051184.0555

${ }^{1}$ A Boci, ${ }^{1} E$ Hallkaj, ${ }^{2}$ R Bani. ${ }^{1} S T O P$ AIDS NGO, Tirane, Albania; ${ }^{2}$ Institute of Public Health, Tirane, Albania

Background HIV and Hepatitis C virus (HCV) infection is one of the most frequent chronic blood-borne infections among injecting drug users (IDU) causing significant morbidity and mortality among them and their sexual partners. Currently, injection drug use is the dominant risk factor for HIV and HCV transmission due to sharing syringes and drug injection equipment and is implicated in $30-40 \%$ of recent HCV cases in Albania. The objective of this study was to determine the prevalence and risk behaviours of HIV, HCV infection and Syphilis among IDU in Tirana, Albania.

Methodology Data were collected from June to November 2011 among Needle Exchange Program (NEP) users in Tirana, Albania using Respondent-Driven Sampling (RDS). Structured questionnaires were administered to measure drug use and sexual risk behaviours. Rapid test technique was used to determine the HCV, HIV and Syphilis prevalence.

Results 68 (34\%) participants were positive for HCV; 1 (0.5\%) for HIV and 2 (1\%) with Syphilis. Heroin (93.2\%) was the most frequently used drug, followed by diazepam (33.4\%) and cocaine (30\%). Risk factors for HCV infection included unsafe cleaning practises and sharing drug injection equipments. $40 \%$ of IDU have injected with a used needle, $34.1 \%$ sharing needles with 3 or fewer persons and $88 \%$ drew drug solution from a common container. Unsafe sex and multiple drug-using sexual partners were associated with HIV infection.

Discussion Results indicate that HCV prevalence remains unacceptably high among IDU when compared to the estimated HIV or Syphilis prevalence IDU is strongly associated with significant drug use and needle-sharing behaviours. HIV and Syphilis prevalence appear to be low and are mostly associated with sexual risk behaviours. The presence of HIV, HCV and Syphilis among NEP users suggests that these venues provide a good opportunity to provide continues prevention and care services to IDU and their partners.

\section{P3.097 SOCIO-DEMOGRAPHIC CHARACTERISTICS AND DRUG RELATED HIGH RISK BEHAVIOUR IN PEOPLE WHO INJECT DRUGS (PWID) RECENTLY DIAGNOSED HIV POSITIVE IN BARNAUL, RUSSIA}

doi:10.1136/sextrans-2013-051184.0556

'L Zohrabyan, ${ }^{2} \mathrm{~L}$ Sultanov, ${ }^{3} \mathrm{E}$ Demianenko, ${ }^{3} \mathrm{~N}$ Vagaitseva, ' $\mathrm{J}$ Malkin. 'UNAIDS, Regional Support Team, ECA, Moscow, Russian Federation; ${ }^{2}$ Center for AIDS and Infectious Disease Prevention of Altay Krai, Barnaul, Russian Federation; ${ }^{3}$ Altay Kray Public Organization "AntiAIDS-Siberia", Barnaul, Russian Federation

Background In 2012 60.4\% of registered HIV cases were attributed to injection drug use in Russia and is up 8\% in Barnaul (2012). We sought to describe socio-demographic and drug related risk factors among PWI recently diagnosed with HIV in Barnaul, Russia.

Methods A cross sectional survey among PWID using RDS was conducted between August and October 2012. PWID were recruited by 5 PWID "seeds." Blood specimens were collected for HIV and CD4 testing.

Results 500 PWID were surveyed. 251 respondents reported a prior HIV- test result. Of these, $61.2 \%$ (95\% CI: 32.8, 85.0) reported their prior negative result was within the last 18 months, 53 PWID (20\% (95\% CI: 8.9, 29.1)) were HIV+. Median CD4+ count in HIV + was 543 while in HIV- 841 cells $\mathrm{mm}^{3}$ ( $\left.p=0.0001\right)$. Subset of 251 PWID represented predominantly by: male $(64.7 \%$, 95\% CI $53.1,78.9)$, 30-39 years old $(68.8 \%$, 95\% CI 51.4, 82.6), single (56.2\%, 95\% CI 36.5, 65.7), unemployed (74.5\%, 95\% 59.9, 85.8), first injection was at age $<14(46.2 \%, 95 \%$ CI 26.2, 64.4). A majority injected in the last month $(63.9 \%, 95 \%$ CI $51.5,80.7)$ from $\geq 2$ to $\leq$ $9(74.8 \%, 95 \%$ CI 46.7, 96.2) times a day. Predominantly used drugs during the last month were heroin, marijuana $(51.3 \%$, 95\% CI 35.1 , 56.9), and desomorphine (27.9\%, 95\% CI 11.3, 37.6). 85.0\% of PIWD injected in a group with $1-5$ injectors $(95 \%$ CI $67.7,96.5)$ with $>6$ non-sterile injections $(50.1 \%, 95 \%$ CI $26.0,77.6)$ on average and $88.1 \%(95 \%$ CI $70.2,97.1)$ shared paraphernalia. Prevalence of Hep C was $81.7 \%$ (95\% CI $70.3,90.3)$.

Conclusions Even with frequent testing, one fifth of PWID did not know their correct HIV status. This is likely attributable to 